\section{Face-to-face with Sports Medicine Australia. Welcome back!}

\author{
Andrea Britt Mosler (1) ', Myles Calder Murphy (1) 2,3
}

As the world continues to deal with the devasting impact of the COVID-19 pandemic, Sports Medicine Australia (SMA) has resumed face-to-face education events... with an innovative virtual spin. SMA is excited to present the annual conference in Australia's premier sporting city of Melbourne from 6 to 9 October 2021. While Australia's borders remain closed, we welcome high profile international keynote speakers presenting virtually, complemented by an array of high calibre Australian keynote and invited speakers interacting face-to-face. All the usual educational and social components we love about the annual SMA conference will be there to enjoy.

\section{OPTIMISING THE HEALTH AND WELL- BEING OF ATHLETES}

The adaptation and resurgence of outdoor forms of exercise during the COVID-19 pandemic has put a spotlight on sports like running and rowing which can be performed with relatively safe physical distancing. Many of Australia's Olympic Gold medal winning rowers trained on Melbourne's Yarra river leaving their medical teams to manage the longrecognised high prevalence of low back pain. In this issue, important recommendations to assist clinicians working with rowers is provided by the new consensus statement coauthored by world experts led by Dr Wilson (see page 893) on the management of low back pain in rowers, complemented by an editorial on low back pain prevention (see page 886).

Supporting athletes in their pursuit of success necessitates a holistic approach to athlete care. The vital role that sleep plays in recovery, health and well-being in athletes is well understood, but the study

${ }^{1}$ La Trobe Sport and Exercise Medicine Research Centre, La Trobe University-Bundoora Campus, Melbourne, Victoria, Australia

${ }^{2} S$ chool of Nursing, Midwifery, Health Sciences and Physiotherapy, University of Notre Dame Australia, Fremantle, Western Australia, Australia

${ }^{3}$ School of Medical and Health Sciences, Edith Cowan University-Joondalup Campus, Joondalup, Western Australia, Australia

Correspondence to Andrea Britt Mosler, La Trobe Sport and Exercise Medicine Research Centre, La Trobe University - Bundoora Campus, Melbourne VIC 3086, Australia; A.Mosler@latrobe.edu.au by Watson et al (see page 912) highlights the negative impact of injuries on quality of life and sleep in athletes. An athlete's injuries influence more than just their physical performance; they can impact educational and psychosocial function as well which require consideration in the overall management plan. Furthermore, both bodied and para-athletes can go to such great lengths to achieve success they may resort to self-harm, well illustrated in the infographic by Krassioukov et al (see page 937).

\section{MENTAL HEALTH TOO}

Physical activity interventions are often prescribed to improve mental health. In a meta-analysis of 111 studies including 3 million adults worldwide, the evidence presented by Professor Rodney Dishman's team clearly supports this notion (see page 926). Moderate to vigorous physical activity can reduce the incidence and severity of depressive symptoms in adults regardless of global region, gender, age or follow-up period. As clinicians, we need to be confident in our skills to prescribe physical activity to improve the mental health of our patients, but how much physical activity is too much? The paradoxical relationship between sleep quality and high physical activity levels in athletes is discussed in a thoughtprovoking editorial calling for more detailed research to better understand why many athletes sleep poorly (see page $887)$. Interestingly, despite poor sleep quality as elite athletes, US Olympians were found to have a lower risk of death from mental health disorders, substance abuse or suicide than the general population (see page 900). Many inter-related factors were theorised to be responsible, including Olympians having healthier lifestyle habits by maintaining physical activity over their life span, higher ratings on positive personality traits such as self-efficacy and resilience, elevated education levels or better socioeconomic status. Supporting Olympic athletes to persevere with their sporting careers despite setbacks due to injury, poor sleep or selection disappointment may positively influence their lifetime mental health!

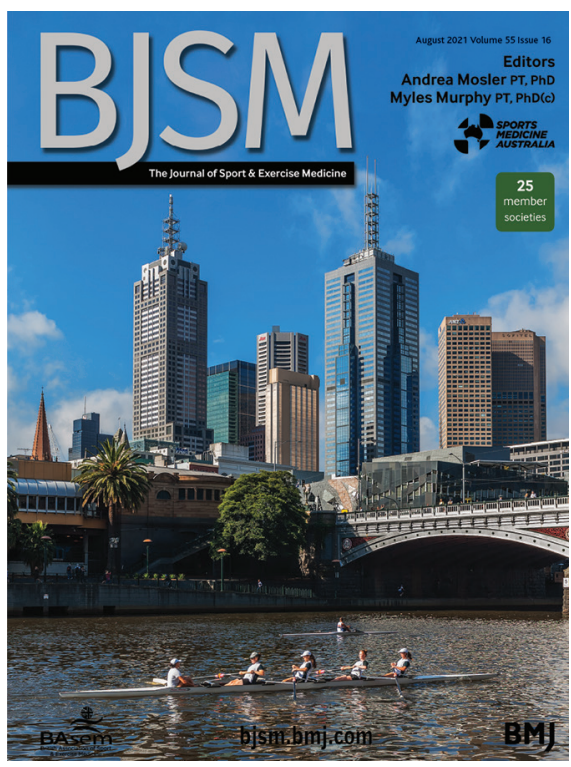

PHYSICAL ACTIVITY - WHO, WHEN AND HOW DO WE MEASURE IT?

The importance of physical activity for mental, physical, social and spiritual health was acknowledged during the COVID-19 lockdowns experienced worldwide. In school children, research continues to highlight the significant role that physical activity plays in youth development. A massive cluster randomised controlled trial conducted by Larsen et al in Denmark (see page 906) examined the benefits of an 11-week 'health education through football' programme for children aged 10-12 years old. Significant improvements were found in the children's health knowledge related to hygiene, nutrition, physical activity and wellbeing. Most importantly though, the children found the programme enjoyable! The importance of considering implementation science when embedding health education in schools, and the potential for such programmes to have a long-term benefit for community health is discussed in an accompanying editorial led by physician and Olympian Dr Jane Thornton (see page 885).

Measuring physical activity accurately and having the information available to the participant improves physical activity behaviour. In a network meta-analysis of 31 studies, McDonough et al (see page 917) determined that simple commercial, wearable health devices are an effective intervention for body weight reduction in overweight/obese individuals with chronic comorbidities. Does this mean that self-reported physical activity data are no longer needed in research? Sattler 


\section{Warm up}

et al (see page 889) discuss the pros and cons of self-reported physical activity data and the need to combine these with device data to provide a holistic picture of physical activity. Finally, Murphy and colleagues consider the context of the athlete environment and value of selfreported exposure metrics which may never be put into use, inaccurate or create unnecessary burden on athletes (see page 891).

We hope you enjoy reading the articles selected for this SMA BJSM edition highlighting research from multidisciplinary fields and, for those who can, we invite you to come to Melbourne for the SMA National Conference, 6-9 October 2021!

Twitter Andrea Britt Mosler @AndreaBMosler and Myles Calder Murphy @myles_physio

Contributors Both ABM and MCM wrote this manuscript.

Funding The authors have not declared a specific grant for this research from any funding agency in the public, commercial or not-for-profit sectors.

Competing interests None declared.

Patient consent for publication Not required.

Provenance and peer review Commissioned; internally peer reviewed.
(C) Author(s) (or their employer(s)) 2021. No commercial re-use. See rights and permissions. Published by BMJ.

\section{(A) Check for updates}

To cite Mosler AB, Murphy MC. Br J Sports Med 2021:55:883-884.

Accepted 8 May 2021

Br J Sports Med 2021;55:883-884. doi:10.1136/bjsports-2021-104455

\section{ORCID iDs}

Andrea Britt Mosler http://orcid.org/0000-0001-73532583

Myles Calder Murphy http://orcid.org/0000-00016068-1096 